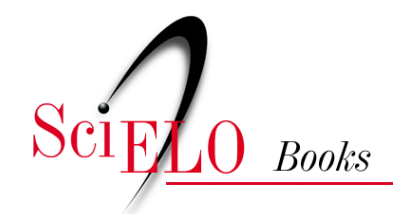

\title{
Revisitando Arthur Ramos \\ a cultura negra e o debate da educação e seu poder de correção e controle social na década de 1930
}

\author{
Monica Luise Santos
}

\section{SciELO Books / SciELO Livros / SciELO Libros}

SANTOS, M.L. Revisitando Arthur Ramos: a cultura negra e o debate da educação e seu poder de correção e controle social na década de 1930. In: SILVA, E.O.C., SANTOS, I.G. and ALBUQUERQUE, S.L., orgs. A história da educação em manuscritos, periódicos e compêndios do $X I X$ e $X X$ [online]. Rio de Janeiro: EdUERJ, 2018, pp. 97-113. ISBN 978-85-7511-483-4.

https://doi.org/10.7476/9788575114834.0007.

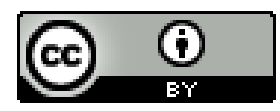

All the contents of this work, except where otherwise noted, is licensed under a Creative Commons Attribution 4.0 International license.

Todo o conteúdo deste trabalho, exceto quando houver ressalva, é publicado sob a licença Creative Commons Atribição 4.0.

Todo el contenido de esta obra, excepto donde se indique lo contrario, está bajo licencia de la licencia $\underline{\text { Creative Commons }}$ Reconocimento 4.0. 


\title{
REVISITANDO ARTHUR RAMOS
}

\author{
A cultura negra e o debate da educação e seu \\ poder de correção e controle social na década de \\ 1930
}

Monica Luise Santos

\section{Introdução}

Nascido na cidade do Pilar, em Alagoas, em 1903, Arthur Ramos iniciou seus estudos primários em sua cidade natal e os completou em Maceió. Segundo Gaspar (2010), já como estudante da Faculdade de Medicina da Bahia, começou a publicar nos jornais de Alagoas e da Bahia artigos sobre o folclore, entre eles estão: $O$ culto da lua na história e no folclore, Tradiçôes africo-brasileiras (1922), A poesia popular(1924) e A ciência do folclore (1924). Ramos dedicou grande parte de sua vida aos estudos sobre o negro e a identidade brasileira.

Nos anos de 1930 e 1940, falar da cultura negra no Brasil era, de certo modo, atravessar as obras escritas por esse antropólogo e médico brasileiro, de cujo conjunto de sua vasta produção se sobressaem os escritos sobre a cultura e a religiosidade da etnia negra. Dentre suas produções sobre essa temática, destacam-se: $O s$ horizontes misticos do negro da Babia (1932); O negro brasileiro: etnografia religiosa e psicanálise (1934); O folclore negro do Brasil: demopsicologia e psicanálise (1935); As culturas negras no Novo 
Mundo (1937); A aculturação negra no Brasil (1942); Guerra e relações de raça (1943); e, postumamente, foram publicadas $A$ mestiçagem no Brasil em Paris (1952)1 e O negro na civilização brasileira (1956).

Essas obras tiveram um papel fundamental no embate com as teorias racistas, consolidadas no século XIX, a partir dos estudos do Conde de Gabineu (1816-82), que defendia a tese da superioridade da raça ariana e, depois, com o Darwinismo Social, a tese da sobrevivência do mais forte, juntamente com a do Evolucionismo Social, que acreditava na evolução das sociedades de um estado primitivo para o civilizado. Todas essas teorias particularizavam o negro como geneticamente inferior. No Brasil, vários intelectuais do final do século XIX e início do XX foram adeptos dessas teorias, entre eles, Nina Rodrigues, Euclides da Cunha e Sílvio Romero.

Décadas depois dos estudos desses intelectuais brasileiros, Arthur Ramos elaborou uma leitura culturalista da etnia negra, apropriando-se do conceito de base psicanalítica, em sua fase inicial de pesquisa, e, depois, da Antropologia. Em seus escritos, defendeu a tese de que o negro não deveria ser concebido como uma raça degenerada, como afirmavam as ciências racistas. Mais precisamente na obra $A$ criança problema, o autor alertou para que não se interpretassem problemas sociais e culturais como de origem genética ou biológica. Assim, ele buscou, naquela geração de intelectuais, esboçar uma reflexão sobre a cultura negra a fim de solucionar os problemas sociais, antes atribuídos às "raças", e deslocá-los para o âmbito social.

Desse modo, nosso objetivo neste estudo é tentar captar o entendimento de Arthur Ramos em relação à cultura negra e seu valor na constituição e formação do negro. Em outras palavras, qual

1 A obra apenas é publicada no Brasil em 2004. 
o lugar da cultura negra nos escritos de Arthur Ramos? Qual sua leitura sobre a cultura afro-brasileira e o valor atribuído à educação? Qual o limite de suas abordagens considerando sua época?

\section{As teorias racistas e a questão da cultura negra no Brasil}

Desde meados do século XIX, o pensamento intelectual brasileiro passou a ser influenciado pelas teorias racistas vindas da Europa, como o Positivismo, o Evolucionismo e o Darwinismo Social. Todas tendo como questão comum a legitimação das desigualdades sociais, as quais apresentavam o branco europeu como etnia superior. Menezes (2002, p. 98) destaca que: "A nação brasileira foi pensada em termos de raça, antes mesmo de ser pensada em termos de cultura ou economia".

Com a chegada da República, houve a preocupação do governo e de intelectuais da época em conter a população negra e mestiça então livre, concebidas como inferiores, imorais, indolentes e degeneradas. Para eles, uma população composta desses tipos raciais teria como consequência a não evolução da nação brasileira para o estágio de sociedade civilizada.

$\mathrm{Na}$ mesma perspectiva de Menezes, Kabengele Munanga (2003, p. 54) adverte que "A pluralidade racial nascida do progresso colonial representava, na cabeça dessa elite, uma ameaça e um grande obstáculo no caminho da construção de uma nação que se pensava branca". Um dos muitos intelectuais do final do século XIX e início do XX que comungava dessa opinião era Euclides da Cunha (1902). Para ele,

[...] a mistura de raças mui diversas é, na maioria dos casos, prejudicial. Ante as conclusões do evolucionismo, ainda quando reaja sobre o produto o influxo de uma raça superior, 
despontam vivíssimos estigmas da inferior. A mestiçagem extremada é um retrocesso (p. 141).

Outro intelectual brasileiro que compartilhava dessa ideia era o médico maranhense Nina Rodrigues, sendo este o principal representante dos estudos sobre o negro de sua época. Influenciado por cientistas estrangeiros, defendeu a tese de que os negros e mestiços eram seres humanos inferiores e degenerados tanto biologicamente quanto culturalmente. Mesmo concebendo o negro como ser rebaixado, Nina Rodrigues não deixou de ressaltar a contribuição daquela etnia para a sociedade brasileira. Em sua clássica obra Os africanos no Brasil (1933)², argumenta que

A raça negra no Brasil, por maiores que tenham sido os seus incontestes serviços à nossa civilização, por mais justificadas que sejam as simpatias de que a cercou o revoltante abuso da escravidão, por maiores que se revelem os generosos exageros dos seus turiferários, há de constituir sempre um dos fatores de nossa inferioridade como povo (Rodrigues, 2010, pp. 14-5).

Para Nina Rodrigues, essa “inferioridade” da população brasileira, composta por homens de cor, apenas seria combatida com a vinda da imigração europeia para o Brasil, que teria como consequência o branqueamento biológico da população. Nas primeiras décadas do século XX, chegou ao país o discurso eugênico que pretendia um "melhoramento da raça" negra por meio do cruzamento com a etnia considerada superior, ou seja, a branca, época

2 Esta obra foi lançada postumamente. Nina Rodrigues não chegou a concluí-la, segundo Souza (2013), a obra foi acabada graças aos trabalhos dos membros da "escola Nina Rodrigues" que reuniram os cadernos e documentos. 
em que o Brasil pretendia alcançar o modelo de modernidade já presente nos países europeus e nos Estados Unidos.

\section{A cultura negra em Arthur Ramos}

Como assinalado, o antropólogo alagoano Arthur Ramos foi um dos primeiros estudiosos brasileiros que tentou inverter a condição do negro como ser biologicamente inferior. Mesmo contrário à teoria da inferioridade biológica, tese defendida por Nina Rodrigues, Arthur Ramos teve o médico maranhense como mestre em relação aos estudos sobre o negro. Em suas obras, Ramos tece elogios aos estudos do pensador maranhense por ele ser o pioneiro nos estudos da questão negra no Brasil, como ele salienta no prefácio da obra O folclore negro do Brasil (2007):

No decorrer desse largo período de 'scotoma' para o problema da raça negra no Brasil, apenas se salvou a obra de Nina Rodrigues. Eu não me canso, em meus estudos atuais sobre o negro brasileiro, de chamar a atenção para os trabalhos de Nina Rodrigues, na Bahia, ponto de partida indispensável ao prosseguimento de um estudo sistematizado e sério sobre a questão (p. 4). ${ }^{3}$

Para o antropólogo alagoano, as impressões negativas atribuídas ao negro por Nina Rodrigues eram motivadas pelos estudos limitados de sua época, contaminados pelas teorias racistas europeias que justificavam a inferioridade do negro. No seu primeiro estudo sobre o negro, Os horizontes místicos do negro na Babia (1932), o autor ressalta que a visão constituída pelo médico maranhense deu-se porque "na sua época, não contou Nina Rodrigues

3 A primeira edição do livro O Folclore Negro no Brasil foi publicada em 1935. 
com esses métodos novos da psychologia comparada que os estudos de Lévy-Bruhi vão tornando clássicos” (Ramos, 1932, p. 40).

Os escritos de Arthur Ramos estão situados numa época na qual havia um tímido ensaio sobre o valor do negro e de sua cultura. Assim como ele, Gilberto Freyre se opôs ao determinismo biológico das teorias racistas. Freyre insistiu em dizer que "a miscigenação racial, característica do Brasil, era um fato positivo, talvez a mais importante e melhor herança herdada da colonização portuguesa" (Oliveira, 2002, p. 41). Entretanto, Menezes (2002) lembra que, apesar dos dois intelectuais repudiarem a noção de inferioridade racial, ambos introduziam noções de psicologia e eugenia, o que acabava por tornar suas frases carregadas das conotações biológicas das quais pretendiam se desfazer.

$\mathrm{Na}$ década de 1930, com o declínio das teorias racistas, tão aceitas pelos intelectuais da segunda metade do século XIX e início do XX, surgiu no panorama intelectual brasileiro o interesse pelo tema das relações raciais, inseridas agora numa discussão de valorização dos negros pela produção científica, tornando-se objeto de estudo dos "antropólogos culturalistas" europeus e norteamericanos, como Roger Bastide (1898-1974). Estes passaram a influenciar intelectuais brasileiros, como Arthur Ramos, embora houvesse um grande grupo de intelectuais, como Oliveira Viana, que ainda permaneceria com a vertente racista em seus estudos.

A produção intelectual relacionada aos negros não despertava apenas o interesse no meio acadêmico, mas também do Estado brasileiro. A política varguista, conforme Tamano (2013, p. 153), "[...] buscava mesclar a diversidade cultural existente no país a fim de encontrar uma espécie de “'essência' brasileira”". Com esse ideal, o negro passava a ser visto pela sociedade como parte integrante dela. É provável que os estudos culturalistas do intelectual alagoano tenham tido boa receptividade dentro do governo Vargas, em razão de ter esse apelo regenerador da mente e do corpo dos indi- 
víduos de etnia negra, princípios esses que estavam alinhados aos governos nazifacistas europeus.

A produção de Arthur Ramos, que é extensa, foi sendo acomodada também à política do Estado brasileiro quando ele participou da Diretoria do Serviço de Ortofrenia (que defendia a correção de um estado mental) e Higiene Mental do Distrito Federal (atual Estado do Rio de Janeiro), em conjunto com Anísio Teixeira. A sua colaboração com estudos sobre os aspectos psicossociais da população o levou a ter destaque no cenário educacional do período.

Seus estudos foram beneficiados pelo novo cenário intelectual brasileiro dos anos 1930. Portanto, a questão negra tinha como referência a Psicanálise de Freud e os estudos do sociólogo e filosofo francês Lévy-Bruhl. Este último defendia a tese de que as sociedades classificadas como "atrasadas", a exemplo da brasileira, tinham a mentalidade pré-lógica.

Em O negro Brasileiro, esclarece que, "estudando, neste ensaio, 'as representações coletivas' das classes atrasadas da população brasileira, no setor religioso, não endosso absolutamente, como várias vezes tenho repetido, os postulados de inferioridade do negro e da sua capacidade de civilização" (Ramos, 1934, p. 30). Em continuação, o alagoano afirma que a questão não era racial, mas psicológica, pois a etnia negra cultivava um pensamento mágico e pré-lógico:

Essas representações coletivas existem em qualquer tipo social atrasado em cultura. É uma consequência do pensamento mágico e pré-lógico, independente da questão antropológico-racial, porque podem surgir em outras condições e em qualquer grupo étnico. [...] Esses conceitos de 'primitivo', de ‘arcaico' são puramente psicológicos e nada têm que ver com a questão de inferioridade racial (p. 32). 
Embora defendesse a igualdade entre as raças do ponto de vista biológico, o antropólogo não deixou de ressaltar que existiam culturas "adiantadas" e "atrasadas". Nesse sentido, Ramos conseguiu romper com uma leitura míope da geração de Nina Rodrigues e caiu numa outra própria de sua época. Como salienta Souza (2013), "o autor retira o problema do negro dos campos racial e médico-biológico, levando-o para o campo cultural”. No entanto, é preciso dizer que Arthur Ramos não aplicou a noção de atraso cultural somente ao negro, mas também a todos os grupos étnicos que se encontravam sem acesso à formação letrada, e que, dessa maneira, não haviam desenvolvido o campo racional tal como supostamente acontecia com aqueles que frequentavam os espaços escolares e acadêmicos.

É necessário dizer que essa forma de conceber a cultura negra esteve circunscrita pelos limites do pensamento de sua época. Os intelectuais da geração de Ramos cultivavam uma leitura preconceituosa do negro. E dificilmente eles escapariam dessa linha de pensamento naquele período. Embora tivesse conseguido ultrapassar o preconceito racial da geração de Nina Rodrigues, a geração do antropólogo alagoano tinha uma confiança quase cega no poder da razão e das letras na formação de sujeitos capazes de vencer os vícios e hábitos e serem moralmente justos. Nesse sentido, a educação seria o meio para corrigir os comportamentos considerados inadequados para uma nação que se pretendia moderna, ou seja, a educação era vista, percebida ou apresentada como a solução para os problemas sociais. Dávila (2006, p. 58) lembra que, "embora o Brasil tivesse chegado ao século XX sob o peso do racismo científico e o estigma que ele aplicava à nação racialmente mista, essa corrente logo deu lugar ao enfoque ambiental e cultural da degeneração".

A cultura e a religiosidade negra, assim como daqueles grupos socialmente rebaixados, para Arthur Ramos, mantinha-se numa mentalidade pré-lógica e primitiva, como já salientamos. E essa 
mentalidade representaria um prejuízo para a nação brasileira, que deveria ser sanado pela higienização e particularizado pela educação.

Já temos mostrado, em mais de um trabalho, os perigos dessa mentalidade pre-lógica, no Brasil, denunciando certos fenômenos de feitiçaria, baixo-espiritismo, demonopatias e outros, e sua nefasta influência na formação da personalidade. Dada a sua extensão, apenas abordamos aqui de leve o tema, que está a exigir um exame sério dos nossos administradores de saúde. O pauperismo, as condições deficitárias de saúde e higiene, a sub-alimentação, a incultura... geram inferioridades de toda a sorte, orgânicas e mentais (Ramos, 1939, pp. 38-39).

Como podemos constatar, havia um discurso médico para justificar a correção das condições materiais e mentais de uma população, supostamente desvirtuada do ponto de vista da conduta humana daquela época. Nesse período, a medicina e a educação caminharam juntas para pôr fim aos comportamentos considerados socialmente desajustados.

Os estudos de Garcia (2010) ressaltam que essa concepção de Arthur Ramos não o tornava racista, e quem utilizou esse argumento para classificá-lo como tal cometeu um julgamento injusto.

Sobre a utilização do conceito de mentalidade primitiva que serviu para qualificar Ramos como racista, como foi o caso da interpretação de Dávila (2006), fazia-se necessário relativizar um pouco a questão, a fim de não cair em um julgamento injusto sobre a obra e o pensamento do médico alagoano. Como já havia afirmado o autor, o conceito de Lévy-Bruhl não se aplicava a um grupo étnico específico e nem tinha uma conotação étnicoracial na medida em que 
poderia ser aplicado às crianças, alienados, comunidades primitivas e até mesmo em indivíduo vivendo em sociedade urbana e industrializada. (Garcia, 2010, p. 92).

Considerando os ideais da época, não seria possível, então, articular ou atribuir um valor positivo à cultura negra nos anos 30 e 40 do século XX. Pois, os limites do ponto de vista intelectual daquela geração ainda não conseguiam ultrapassar a barreira de uma mentalidade na qual o modelo de homem, de cultura e de sociedade era o europeu, com seu pensamento etnocêntrico.

\section{Arthur Ramos e a correção de condutas pela educação}

Em meados do século XX, o sistema educacional brasileiro era para poucos, afirmando em sua organização ideologias europeias, e continuava com os discursos de intelectuais de que os males sociais seriam corrigidos pela educação. Nesse contexto, as ideias da Escola Nova chegaram ao Brasil com o objetivo de mudar o cenário da educação nacional, sobretudo aquela destinada às escolas primárias, cujo principal foco passou a ser a criança, e um ensino que conduzisse à autonomia do educando. Os ideais da Escola Nova no Brasil tinham como seu principal representante Anísio Teixeira. Sobre esse intelectual salienta Sircilli (2005):

Teixeira era marcadamente influenciado pelo filósofo-educador norte-americano John Dewey, para quem a educação deveria manter o equilíbrio entre o homem e suas particularidades psicológicas, de um lado, e as exigências da sociedade em que vivia, de outro (Sircilli, 2005, p. 189).

Arthur Ramos não escapou a essas concepções e foi influenciado pelas ideais da Escola Nova. Garcia (2010) chama atenção 
para o fato de que, para o autor alagoano, embora o objeto pedagógico da Escola Nova fosse centrado na criança, seu objetivo mais importante era para como a sociedade, uma vez que ambicionava produzir indivíduos capazes de atuar nas diferentes necessidades da vida em constante transformação. Garcia (2010, p. 114) ressalta ainda que "para que isso ocorresse era fundamental que a pedagogia baseada na própria experiência que acumulou ao longo dos tempos auxiliasse os indivíduos a encontrarem seu caminho".

Em 1933, Arthur Ramos foi convidado por Anísio Teixeira para dirigir o Serviço de Ortofrenia e Higiene Mental do Instituto de Pesquisas Educacionais (IPE), do Rio de Janeiro. Ao dirigir o referido Instituto, Arthur Ramos também aproveitou para realizar pesquisas para seus futuros trabalhos na área educacional, como as obras Saúde do espirito (1939) e A criança problema (1939), as quais davam orientações educacionais para pais e educadores. Dávila (2003) lembra que o Rio de Janeiro se tornou, nesse período, um imenso laboratório para as ideias eugênicas.

Para atender ao projeto de formar uma "raça" brasileira, cientistas e médicos começaram a fundar, nas décadas de 1920, sociedades eugênicas no Brasil. Entre os adeptos estavam intelectuais e educadores brasileiros, como Fernando de Azevedo, Edgar Roquete Pinto e Afrânio Peixoto. Para os intelectuais, a escola seria o meio de pôr em prática ideias eugênicas: "O consenso entre os formuladores de políticas era que as escolas eram as linhas de frente da batalha contra a 'degeneração'. Os educadores transformaram as escolas em laboratórios-lugares onde ideias sobre a raça e nação eram testadas e aplicadas sobre as crianças”. (Dávila, 2006, pp. 556). O autor classifica Arthur Ramos como integrante desse bloco intelectual eugênico. Na obra Saúde do espírito, Ramos se opôs a uma eugenia racial, mas não cultural:

Todo um capítulo da chamada 'higiene racial' tem de ser revisto aqui. No Brasil, especialmente, muito se clamou, 
era voz de alguns teóricos estrangeiros (e alguns nacionais!), que somos um 'povo inferior provindos de 'raças inferiores', que aqui cruzaram as suas 'hereditariedades desharmonicas”. O negro foi a nossa perdição! - Clamaram alguns. Devemos voltar ao ariano! Só pelo cruzamento com o branco, voltaremos ao ariano! - Gritaram outros.

Esses falsos cientistas acharam ainda que a mestiçagem era um fator de 'degenerescência'. Uma das causas do nosso atraso estava no mestiço desharmônico, incapaz, inferiorizado.

O que se atribuía a um mal de raça verificou-se que era um mal de condições higiênicas deficitárias: sub-alimentação, pauperismo, doenças, alcoolismo... carregando no seu bojo toda a sorte de 'inferioridade'.

Não precisamos de cruzamentos eugênicos. Precisamos é melhorar o que temos. Os estudos contemporâneos de um grupo de pesquisadores brasileiros, [...] veem clamando que a pretensa inferioridade do mestiço brasileiro melhorará e desaparecerá quando cessarem os déficits ambientais de toda a natureza (Ramos, 1939, pp. 38-9).

Para Garcia (2006), o médico alagoano não fazia parte da ciência eugênica, pois apenas queria uma melhor condição de vida para o negro. No entanto, o próprio Arthur Ramos classifica a Higiene Mental como um modelo preventivo e de correção de conduta. Pinheiro (2015) destaca que no livreto Família e escola, escrito por Ramos em 1934, evidenciava que higiene mental estava muito mais ligada ao trabalho preventivo que o de correção. Mas, em $O$ negro brasileiro, Ramos deixou claro o poder da educação para corrigir as práticas culturais inferiores.

Assim, para a obra da educação e da cultura, é preciso conhecer essas modalidades do pensamento 'primitivo' para 
corrigi-lo, elevando-o a etapas mais adiantadas, o que só será conseguido por uma revolução educacional que aja em profundidade, uma revolução 'vertical' e 'intersticial' que desça aos degraus remotos do inconsciente coletivo e solte as amarras pré-lógicas a que se acha acorrentado (Ramos, 1940, p. 31).

Ainda em $O$ negro brasileiro, Ramos também evidencia seu conceito de inferioridade atribuído à cultura negra. Segundo ele, se não estudasse as mentalidades da classe "atrasada", a obra da educação não poderia ser realizada, bem como prejudicaria o trabalho dos professores e higienistas.

Transportando-me para o Rio de Janeiro, fui honrado com o convite de Anisio Teixeira para instalar um Serviço de Higiene Mental nas Escolas do Distrito Federal. Entre outros afazeres deste Serviço, pus-me a estudar a população dos morros do Rio de Janeiro e por ai, progressivamente, penetrei no reconcílio das macumbas e dos centros de feitiçaria. Deste modo, o presente trabalho não deixa de ter um largo alcance higiênico e educacional. Evidentemente nada teremos realizado em matéria de educação se, preliminarmente, não procurarmos conhecer a própria estrutura dinâmico-emocional da nossa vida coletiva. E todo o trabalho resultará improfícuo se não desenredarmos todas as tramas inconscientes do logro e da superstição, impedindo que uma resistência surda e insidiosa vá desmanchar posteriormente todo o árduo trabalho dos educadores e dos higienistas (Ramos, 1940, p. 30).

Observamos nas falas apresentadas que o preconceito contra o negro ou a correção moral e comportamental ainda estavam presentes nesse intelectual, que se posicionou como crítico das teorias racistas do século XIX e ainda difundidas nas primeiras décadas 
do século XX. Arthur Ramos, como os outros intelectuais, considerava a educação como um processo de branqueamento do negro, do ponto de vista da cultura. Nesse sentido, o antropólogo apresentou as mesmas opiniões defendidas por intelectuais do século XIX, ainda que se posicionasse contrário à inferioridade biológica do negro e do mestiço (Santos, 2008). Pinheiro (2015) salienta que, embora o antropólogo não defendesse a inferioridade do negro, ele esbarrou "numa visão problemática sobre outro tipo de hierarquização, o das culturas". Supondo sair em defesa das "culturas atrasadas", defende a capacidade delas de "evoluir", de se civilizar, superando seus supostos atrasos, "milagre" somente possível graças à educação" e seu poder correcional.

É necessário ressaltar que o conjunto de intelectuais dos anos de 1920 a 1940 não escapou de uma leitura evolucionista da humanidade impulsionada pelo desenvolvimento racional e moral da escola.

\section{Considerações finais}

É possível concluir que os estudos de Arthur Ramos sobre as relações ente a cultura negra e a educação, levando em consideração os limites de sua época, contribuíram para revogar a tese da inferioridade biológica do negro, mas, ao mesmo tempo, permaneceu a tese da inferioridade cultural das populações que não tinham acesso ao saber letrado, como se os argumentos relacionados à cultura não fossem um aspecto de rebaixamento de um povo. Para Ramos, esses grupos considerados atrasados culturalmente apenas evoluiriam por meio da educação escolar, que era considerada pelos intelectuais como a chave para se alcançar o progresso e a civilização do país.

Com essa concepção, Arthur Ramos acabou compartilhando das mesmas leituras de seus pares em relação ao povo brasileiro e contribuindo, assim, para que a população negra ainda perma- 
necesse à margem da sociedade brasileira. Com esse propósito, Ramos compartilhava da intenção política do Estado brasileiro Varguista de formar uma nação moderna e consequentemente civilizada, moldada ao conceito cultural e moral da Europa.

Do mesmo modo que no projeto político nacional, esses homens considerados de letras, como Ramos, compreendiam que a educação escolar era a chave para atenuar os comportamentos desviantes, e, sobretudo, corrigir a inferioridade cultural dos grupos supostamente "atrasados", e, assim, corrigir cotidianamente pensamentos e hábitos, educar o corpo, os sentidos e os gestos, para atender uma sociedade que demandava novos sujeitos, agentes da nação.

\section{Referências}

CUNHA. Euclides. Os sertóes (Campanha de Canudos). São Paulo: Martin Claret, 2006. (Coleção Obra Prima de Cada Autor).

DÁVILA, Jerry. Diploma de brancura: politica social e racista no Brasil (1917-1945). São Paulo: UNESP, 2006.

GARCIA, Ronaldo Aurélio Gimenes. A trajetória intelectual de Arthur Ramos: higiene mental e criança problema (1939-1949) (dissertação). Universidade Federal de São Carlos, 2010.

GASPAR, Lúcia. Arthur Ramos. Fundação Joaquim Nabuco, Recife, 2010. Disponível em: http://basilio.fundaj.gov.br/pesquisaescolar. Acesso em: 17 jun. 2016

MENEZES, Maria Odete. A psicanálise na Babia (1926-1937): os estudos de Arthur Ramos sobre a loucura, educação infantil e cultura (dissertação). Universidade Federal da Bahia e Universidade Estadual de Feira de Santana, 2002. 
MUNANGA, Kabengele. Rediscutindo a mestiçagem no Brasil: identidade nacional versus identidade negra. 2 ed. Autêntica, 2004.

OLIVEIRA, Laiana Lannes de. A frente negra brasileira: politica e questão racial nos anos 1930 (dissertação). Universidade do Estado do Rio de Janeiro, 2002.

PINHEIRO, José Gledison Rocha. O diário de Dalila: poética, testemunho e tragédia na formação escolanovista do indivíduo moderno (1933-1934) (tese). Universidade Federal da Paraíba, 2015.

RAMOS, Arthur. Os horizontes misticos do negro na Babia. s/e, 1932.

. As culturas negras no Novo Mundo. Rio de Janeiro: Civilização Brasileira, 1937

. Saúde do espirito: higiene mental. Rio de Janeiro: Departamento Nacional de Saúde, 1939.

. O negro brasileiro. 2 ed. São Paulo: Cia. Editora Nacional, 1940.

. Aculturação negra no Brasil. São Paulo: Cia. da Editora Nacional, 1942.

. Guerra e relações de raça. Rio de Janeiro: Gráfica Perfecta, 1943.

. O negro na civilização brasileira. Rio de Janeiro: Casa do Estudante do Brasil, 1956.

. A mestiçagem no Brasil. Maceió: Edufal, 2004. . Folclore negro no Brasil. São Paulo: Martins Fontes, 2007. 
RODRIGUES, Nina. Os africanos no Brasil. Rio de janeiro: Biblioteca Virtual de Ciências/Centro Edelstein de Pesquisas Sociais: 2010. Disponível em: http://www.ufgd.edu.br/reitoria/neab/downloads/os-africanos-no-brasil. Acesso em: 9 out. 2011.

SANTOS, Monica Luise. A educação de meninos negros na Escola Central em Maceió (1881-1893) (Trabalho de Conclusão de Curso - Pedagogia). Universidade Federal de Alagoas, 2008.

SIRCILLI. Fabíola. "Arthur Ramos e Anísio Teixeira na década de 1930”. In: Paidéia, 2005 Disponível em: http://www.scielo. br/pdf/paideia/v15n31/06.pdf. Acesso em: 26 jun. 2013.

SOUZA, Fabíola Amaral Tomé de. A presença do negro no pensamento social brasileiro. 2013. Disponível em: http://www.educacaopublica.rj.gov.br/biblioteca/historia/0110.html. Acesso em: 22 jun. 2013.

TAMANO, Luana Tieko. Arthur Ramos e a mestiçagem no Brasil. Maceió: Edufal, 2013. 